\title{
GAMBARAN STATUS KEBERSIHAN GIGI DAN MULUT BERDASARKAN INDEKS PHP PADA PASIEN PENGUNJUNG POLI GIGI DI PUSKESMAS POIGAR KABUPATEN BOLAANG MONGONDOW SULAWESI UTARA
}

\author{
Dian Tambun ${ }^{1}$, Vega Roosa Fione ${ }^{2,}$ Made Yuliana ${ }^{3}$ \\ 1)Pukesmas Poigar Kab.Bolaang Mongondow Jl.Trans Sulawesi Sulawesi Utara \\ 2,3) Jurusan Keperawatan Gigi Poltekkes Kemenkes ManadoJl.RW Mongisidi Malalayang II Manado \\ Email : vegaroosafione@gmail.com
}

\begin{abstract}
ABSTRAK
Pendahuluan : Plak gigi merupakan deposit lunak yang merekat erat pada permukaan gigi, terdiri atas mikroorganisme yang berkembang biak dalam suatu matrik interseluler jika seseorang melalaikan kebersihan gigi dan mulutnya. Mekanisme pembentukan plak dimulai dengan terbentuknya acquired pellicle pada permukaan gigi yang berwarna transparan, kemudian bakteri akan menempel dan berproliferasi sehingga warna gigi akan menjadi agak kekuningan. Factor-faktor yang mempengaruhi pembentukan plak gigi adalah lingkungan fisik, friksi atau gesekan oleh makanan yang dikunyah, pengaruh diet terhadap pembentukan plak telah diteliti dalam dua aspek yaitu pengaruhnya secara fisik dan pengaruhnya sebagai sumber makanan bagi bakteri didalam plak, jenis makanannya yaitu keras dan lunak. Tujuan penelitian untuk mengetahui gambaran status kebersihan gigi dan mulut berdasarkan indeks PHP pada pasien pengunjung poli gigi di Puskesmas Poigar. Metode : Penelitian ini menggunakan metode deskriftif dengan menggunakan distribusi presentase. Penelitian dilakukan pada bulan Mei 2019 bertempat di Poli Gigi Puskesmas Poigar dan sampel yang digunakan 31 responden dengan menggunakan instrument yaitu diagnose set dan disclosing solution serta format penilaian indeks PHP, data yang diperoleh kemudian ditabulasi dan disajikan dalam bentuk tabel distribusi frekuensi disertai penjelasan. Hasil : Data hasil penelitian dikelompokkan berdasarkan kelompok umur, jenis kelamin dan skor indeks PHP. Hasil penelitian menunjukkan indeks PHP kriteria sedang 15 responden $(48,4 \%)$, kriteria buruk 10 responden $(32,2 \%)$ dan kriteria baik berjumlah 6 responden $(19,4 \%)$. Kesimpulan : sebagian besar responden mempunyai kebersihan gigi dengan kriteria sedang.
\end{abstract} Kata Kunci : Kebersihan Gigi dan Mulut, Plak gigi, PHP Indeks

\begin{abstract}
Introduction: Dental plaque is a soft deposit that adheres tightly to the surface of the teeth, consisting of microorganisms that reproduce in an intercellular matrix when a person neglects the hygiene of his teeth and mouth. The mechanism for plaque formation begins with the formation of acquired pellicles on the surface of the teeth which are transparent, then bacteria will stick and proliferate so that the color of the teeth will be slightly yellowish. The factors that influence the formation of dental plaque are the physical environment, friction or friction by chewing food, the effect of diet on plaque formation has been studied in two aspects, namely its physical effect and its effect as a food source for bacteria in plaque, the type of food is hard and soft. . The aim of this study was to describe the status of oral hygiene based on the PHP index in dental clinic visitors at Poigar Public Health Center. Methods: This study uses descriptive methods using a percentage distribution. The research was conducted in May 2019 at the Poigar Public Health Centre and the sample used by 31 respondents using instruments, namely the diagnosis set and disclosing solution as well as the PHP index assessment format, the data
\end{abstract}


obtained was tabulated and presented in the form of a frequency distribution table accompanied by an explanation. Results: The research data were grouped by age group, gender and PHP index score. The results showed the PHP index criteria were 15 respondents $(48.4 \%)$, bad criteria were 10 respondents (32.2\%) and good criteria were 6 respondents (19.4\%). The conclusion of this study shows that the PHP index of visitors to the Poigar Dental Clinic visitors are diligent in cleaning their teeth by brushing their teeth properly and properly and having their teeth checked every 6 months or 1 year 2 times.

Keywords: Teeth and Oral Hygiene, Dental Plaque, PHP Index

\section{PENDAHULUAN}

Kebersihan gigi dan mulut adalah bebasnya mulut dari sisa-sisa makanan yang telah mengandung bakteri dan kuman yang merusak atau disebut juga debris. Kuman-kuman yang merusak gigi banyak terdapat dalam plak. Plak yang merekat erat pada permukaan gigi dan gingival berpotensi cukup besar untuk menimbulkan penyakit pada jaringan keras gigi maupun jaringan pendukungnya. ${ }^{1}$

Berdasarkan data Riset Kesehatan Dasar (RISKESDAS) tahun 2018 proporsi penduduk Indonesia yang bermasalah dengan kesehatan gigi dan mulut mencapai 66,5 \%. Ditemukan sebagian besar penduduk Indonesia menyikat gigi pada saat mandi pagi dan mandi sore, $(94,7 \%)$. Menyikat gigi dengan benar adalah setelah makan pagi dan sebelum tidur malam, untuk Indonesia ditemukan hanya $2,8 \%{ }^{2}$

Mengukur kebersihan gigi dan mulut merupakan upaya untuk menentukan keadaan kebersihan gigi dan mulut. Salah satu indeks untuk mengukur kebersihan gigi dan mulut yaitu Indeks PHP. Plak gigi merupakan deposit lunak yang melekat erat pada permukaan gigi, terdiri atas mikroorganisme yang berkembang biak dalam suatu matrik interseluler jika seseorang melalaikan kebersihan gigi dan mulutnya. Mekanisme pembentukan plak dimulai dengan terbentuknya acquired pelicle pada permukaan gigi yang berwarna transparan, kemudian bakteri akan menempel dan berproliferasi sehingga warna gigi akan menjadi agak kekuningan. Pelikel terdiri dari glikoprotein yang diendapkan oleh saliva yang terbentuk setelah proses penyikatan pada gigi. Perkembangbiakan bakteri akan menjadikan lapisan plak semakin menebal karena adanya hasil dari metabolisme dan adhesi dari berbagai macam bakteri pada permukaan luar plak gigi ${ }^{1}$

Podshadley dan Haley (1968) dalam Pintaulli dan Hamada, (2010) menjelaskan bagaimana cara pemeriksaan indeks plak Personal Hygiene Performance (PHP) sebagai berikut:

1) Untuk memeriksa plak yang terbentuk pada permukaan gigi bisa dengan menggunakan larutan disclosing solution.

2) Lakukan pemeriksaan mahkota gigi pada bagian fasial atau lingual dengan membagi tiap permukaan mahkota menjadi lima bagian, yaitu D (distal), G (sepertiga tengah gingiva), $\mathrm{M}$ (mesial), C (sepertiga tengah), I/O (sepertiga tengah insisal atau oklusal).

3) Pemeriksaan secara sistematis:

a) Pemeriksaan pada permukaan labial gigi incisivus satu kanan atas.

b) Pemeriksaan pada permukaan labial gigi incisivus satu kiri bawah.

c) Pemeriksaan pada permukaan bukal gigi molar satu kanan atas.

d) Pemeriksaan pada permukaan bukal gigi molar satu kiri atas.

e) Pemeriksaan pada permukaan lingual gigi molar satu kiri bawah. 
f) Pemeriksaan pada permukaan lingual gigi molar satu kanan bawah.

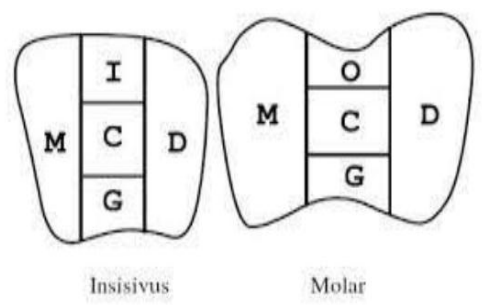

Gambar 1. Pembagian Subdivisi Pemeriksaan Indeks PHP

4) Cara penilaian plak :

Nilai $0=$ tidak terdapat plak

Nilai $1=$ terdapat plak.

5) Untuk menentukan indeks plak Personal Hygiene Performance digunakan rumus :

IP PHP

$=\underline{\text { Jumlah total skor plak seluruh permukaan gigi yang diperiksa }}$

6) Kriteria penilaian : 0 : sangat baik, 0,1-1,7 : baik, 1,8-3,4: sedang, 3,5-5: buruk. $^{3}$

Hasil penelitian oleh Mantiri dkk, (2013) tentang "Status kebersihan mulut dan status karies gigi mahasiswa pengguna alat ortodontik cekat " pada 38 mahasiswa dengan indeks menggunakan indeks PHP menunjukkan 34 orang memiliki kebersihan gigi dan mulut yang baik $(89,47 \%), 4$ orang memiliki kebersihan gigi dan mulut sedang $(10,53 \%){ }^{4}$

Berdasarkan survey awal yang dilakukan di Puskesmas Poigar pada tanggal 26 Maret 2019 diperoleh data kunjungan pasien poli gigi tahun 2018 sebanyak 396 pasien yang berkunjung dan rata - rata pasien dengan keluhan gigi berlubang atau karies gigi. Hasil pemeriksaan pada 5 orang pasien yang datang dengan menggunakan indeks plak PHP semua memiliki kebersihan gigi kategori buruk yaitu 3,7. Dari hasil wawancara pada 5 orang pasien yang diperiksa rata - rata menyikat gigi hanya pada waktu mandi saja.

Tujuan Penelitian ini adalah untuk mengetahui gambaran status kebersihan gigi dan mulut berdasarkan Indeks PHP pada pasien pengunjung poli gigi di Puskesmas Poigar“.

\section{METODE}

Jenis penelitian ini bersifat deskriptif bertujuan untuk menggambarkan atau mendespkripsikan keadaan yang diperoleh di lapangan secara nyata atau factual. ${ }^{5}$.

Waktu penelitian pada Minggu keempat bulan Mei 2019. Tempat penelitian dilaksanakan di Poli Gigi Puskesmas Poigar Kabupaten Bolaang Mongondow

Variabel penelitian ini adalah variabel tunggal yaitu : Mono variable yaitu kebersihan gigi dan mulut berdasarkan Indeks PHP pada pasien pengunjung poli gigi di Puskesmas Poigar.

Populasi yang digunakan dalam penelitian ini yaitu seluruh pasien yang berkunjung di Poli gigi Puskesmas Poigar pada bulan Maret - April 2019 yang berjumlah 82 orang. Sampel yang digunakan dalam penelitian ini menggunakan accidental sampling. Menurut Sugiono (2009). Accidental sampling adalah teknik penentuan sampel berdasarkan kebetulan, yaitu responden yang secara kebetulan/incidental bertemu dengan peneliti dapat digunakan sebagai sampel, bila dipandang orang yang kebetulan ditemui itu cocok sebagai sumber data, dengan jumlah sampel 31 responden. ${ }^{6}$ Dengan kriteria inklusi : bersedia dijadikan objek penelitian dengan berdasarkan persetujuan responden yang dinyatakan didalam informed consent.,berada ditempat pada waktu penelitian

\section{Defenisi Operasional}

1. Kebersihan gigi dan mulut adalah salah satu upaya yang dilakukan untuk meningkatkan derajat kesehatan gigi dan mulut. Kebersihan gigi dan mulut yang diukur menggunakan index PHP merupakan jumlah yang telah diukur dengan ketentuan yaitu dikatakan baik 
jika rata-rata PHP 0,1-1,7, dikatakan sedang jika rata-rata PHP 1,8-3,4 dan buruk jika ratarata PHP 3,5-5,0.

2. Pengunjung Puskesmas adalah Pasien yang dating berkunjung di poli gigi Puskesmas Poigar dan menjadi responden dalam penelitian selama 1 minggu pada minggu keempat bulan Mei tahun 2019.

Instrumen yang digunakan dalam penelitian ini menggunakan format pemeriksaan indeks PHP. Data yang diperoleh kemudian ditabulasi dan disajikan dalam bentuk tabel yang disertai dengan penjelasan. Dengan menggunakan rumus distribusi frekuensi

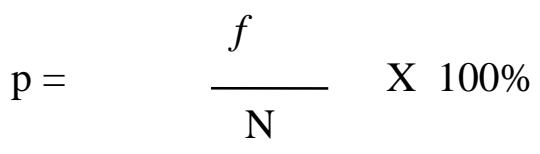

Keterangan :

$\mathrm{F}=$ frekwensi yang sedang dicari

$\mathrm{N}=$ Number of cases (jumlah frekwensi kebanyakan individu)

$\mathrm{P}=$ Angka presentasi $^{9}$

$100 \%=$ nilai konstanta

\section{HASIL DAN PEMBAHASAN}

\section{HASIL}

1. Distribusi Responden Menurut Kelompok Umur

Distribusi responden menurut kelompok umur dapat dilihat pada tabel 1 di bawah ini :

Tabel 1. Distribusi Responden Menurut Kelompok Umur

\begin{tabular}{ccc}
\hline $\begin{array}{c}\text { Kelompok } \\
\text { Umur }\end{array}$ & Jumlah & $\%$ \\
\hline $11-25$ tahun & 6 & 19,4 \\
$25-50$ tahun & 18 & 58,1 \\
$51-65$ tahun & 7 & 22,5 \\
\hline Total & $\mathbf{3 1}$ & $\mathbf{1 0 0}$ \\
\hline
\end{tabular}

Berdasarkan data pada tabel 1 menunjukkan bahwa distribusi responden teringgi pada umur 26 - 50 tahun berjumlah 18 responden $(58,1 \%)$.

2. Distribusi Responden Menurut Jenis Kelamin Distribusi responden berdasarkan jenis kelamin dapat dilihat pada tabel 2 di bawah ini :

Tabel 2. Distribusi Responden Menurut Jenis Kelamin

\begin{tabular}{ccc}
\hline Jenis Kelamin & Jumlah & \% \\
\hline Laki - laki & 13 & 41,9 \\
Perempuan & 18 & 58,1 \\
\hline Total & $\mathbf{3 1}$ & $\mathbf{1 0 0}$ \\
\hline
\end{tabular}

Berdasarkan data pada tabel 3 menunjukkan bahwa distribusi responden tertinggi pada jenis kelamin perempuan yaitu 18 responden $(58,1 \%)$.

3. Distribusi Responden Berdasarkan Kategori Indeks PHP

Distribusi responden berdasarkan kategori indeks PHP dapat dilihat pada tabel 3 di bawah ini :

Tabel 3. Distribusi Responden Berdasarkan Kategori Indeks PHP

\begin{tabular}{ccc}
\hline Kategori & Jumlah & \% \\
\hline Baik & 6 & 19,4 \\
Sedang & 15 & 48,4 \\
Buruk & 10 & 32,2 \\
\hline Total & $\mathbf{3 1}$ & $\mathbf{1 0 0}$
\end{tabular}

Berdasarkan data pada tabel 3 menunjukkan bahwa responden berdasarkan indeks PHP tertinggi yaitu 15 responden $(48,4 \%)$ dalam kategori sedang.

4. Tabel Silang Berdasarkan Kelompok Umur dengan Indeks PHP 
Tabel silang responden berdasarkan kelompok umur dengan indeks PHP dapat dilihat pada tabel 4 di bawah ini :

Tabel 4. Tabel Silang Berdasarkan Kelompok Umur dengan Indeks PHP

\begin{tabular}{|c|c|c|c|c|c|c|c|c|}
\hline \multirow{2}{*}{$\begin{array}{l}\text { Umur } \\
\text { (Thn) }\end{array}$} & \multicolumn{8}{|c|}{ Kriteria Indeks PHP } \\
\hline & Baik & $\%$ & Sedang & $\%$ & Buruk & $\%$ & Jumlah & $\%$ \\
\hline $11-25$ & 4 & 12.9 & 2 & 6.5 & 0 & 0 & 6 & 19.4 \\
\hline $26-50$ & 2 & 6.5 & 10 & 32.3 & 6 & 19.3 & 18 & 58.1 \\
\hline $51-65$ & 0 & 0 & 3 & 3 & 4 & 12.9 & 7 & 22.5 \\
\hline Total & 6 & & 15 & & 10 & & 31 & 100 \\
\hline
\end{tabular}

Berdasarkan data pada table 4 menunjukkan bahwa responden tertinggi pada umur $26-50$ tahun sebanyak 10 responden (32,3\%) dengan kriteria sedang,

5. Tabel Silang Berdasarkan Kelompok Jenis Kelamin dengan Indeks PHP

Tabel silang responden berdasarkan kelompok Jenis Kelamin dengan indeks PHP dapat dilihat pada tabel 5 di bawah ini :

Tabel 5. Tabel Silang Berdasarkan Kelompok Jenis Kelamin dengan Indeks PHP

\begin{tabular}{|c|c|c|c|c|c|c|c|c|}
\hline \multirow{2}{*}{$\begin{array}{c}\text { Jenis } \\
\text { kelamin }\end{array}$} & Baik & $\%$ & $\begin{array}{c}\text { Seda } \\
\mathrm{ng}\end{array}$ & $\%$ & $\begin{array}{c}\text { Buru } \\
\mathrm{k}\end{array}$ & $\%$ & $\begin{array}{c}\text { Jumla } \\
\mathrm{h}\end{array}$ & $\%$ \\
\hline Laki- laki & 3 & 9.6 & 6 & $\begin{array}{c}19 . \\
3\end{array}$ & 4 & 13 & 13 & $\begin{array}{c}41 . \\
9\end{array}$ \\
\hline $\begin{array}{c}\text { Perempua } \\
\mathrm{n}\end{array}$ & 3 & 9.6 & 9 & $\begin{array}{c}29 . \\
2\end{array}$ & 6 & $\begin{array}{c}19 . \\
3\end{array}$ & 18 & $\begin{array}{c}58 . \\
1\end{array}$ \\
\hline Total & 6 & & 15 & & 10 & & 31 & 100 \\
\hline
\end{tabular}

Berdasarkan data pada tabel 5. Menunjukkan persentase tertinggi pada jenis kelamin perempuan dengan kriteria indek PHP sedang sebesar 9 responden $(19.2 \%)$

\section{PEMBAHASAN}

Kebersihan mulut dalam kesehatan gigi dan mulut sangatlah penting. Beberapa masalah mulut dan gigi dapat terjadi karenanya kurang menjaga kebersihan mulut dan gigi. Tujuan menjaga kesehatan gigi dan mulut adalah menghindari lubang pada gigi karena lubang gigi adalah permasalahan utama yang bias menjadi pusat infeksi bagi organ lain didalam rongga mulut. Kebersihan gigi dan mulut harus tetap diperhatikan karena merupakan suatu tindakan preventif bagi setiap individu agar terhindar dari berbagai masalah kesehatan gigi dan mulut. Sebagai akibat kebiasaan yang malas menjaga kebersihan gigi dan mulut maka akan terbentuk plak. $^{7}$

Plak gigi merupakan deposit lunak yang melekat erat pada permukaan gigi, terdiri atas mikroorganisme yang berkembang biak dalam suatu matrik interseluler jika seseorang melalaikan kebersihan gigi dan mulutnya. Jika jumlahnya sedikit plak tidak dapat terlihat kecuali diwarnai dengan larutan disclosing atau sudah mengalami diskolorasi oleg pigmenpigmen yang berada dalam rongga mulut. Jika menumpuk plak akan terlihat berwarna abu-abu, abu-abu kekuningan, dan kuning. Salah satu indeks untuk mengukur kebersihan gigi dan mulut yaitu indeks PHP (Personal Hyguine Performance) dengan kriteria baik, sedang dan buruk. ${ }^{1}$

Hasil dari penelitian ini diperoleh data responden berdasarkan kelompok umur tertinggi pada umur 25 - 50 tahun sebanyak 18 responden $(58,1 \%)$ dan terendah pada responden umur $11-$ 25 tahun sebanyak 6 responden $(19,4 \%)$. Hal ini disebabkan usia 25-50 merupakan usia produktif dengan aktifitas yang tinggi, sehingga dalam menjaga kebersihan gigi dan mulut sering terabaikan. Tuntutan aktifitas dan pekerjaan yang tinggi menyebabkan kesulitan dalam menjaga kebersihan gigi dan mulut karena sepanjang hari mereka bekerja, mereka makan minum maupun merokok sehingga memudahkan perlekatan dari plak. Berdasarkan jenis Kelamin diperoleh data responden dengan jenis kelamin perempuan tertinggi sebanyak 18 responden $(58,1 \%)$ dan 
pada laki - laki hanya 13 responden $(41,9 \%)$. Berdasarkan kategori indeks PHP, sebanyak 10 responden $(32,3 \%)$ dengan kategori sedang dan 6 responden $(19,4 \%)$ dengan kategori baik. Hal ini menunjukkan bahwa responden perempuan mempunyai kebiasaan buruk dalam menjaga kebersihan gigi dan mulut dan berdasarkan hasil wawancara dengan responden rata - rata mempunyai kebiasaan mengkonsumsi makanan yang manis dan mudah melekat serta hanya menyikat gigi pada saat mandi saja. Sebagai tindakan pertama yang dapat dilakukan untuk mencegah atau setidak-tidaknya mengontrol pembentukan plak, adalah dengan membatasi makanan yang banyak mengandung karbohidrat terutama sukrosa. Makanan yang lunak dan mudah menempel pada gigi sebaiknya dihindari. ${ }^{1}$

Pengetahuan juga merupakan salah satu faktor yang dapat mempengaruhi kebersihan gigi dan mulut. Menurut Bloom dalam Notoadmodjo (2007) bahwa perilaku kesehatan gigi dan mulut dibagi menjadi 3 domain yaitu pengetahuan, sikap, praktek atau tindakan. ${ }^{8}$ Hal ini berarti bahwa tidak hanya pengetahuan yang dapat membentuk perilaku seseorang. Pengetahuan seseorang tentang kesehatan gigi akan sangat menentukan status kesehatan gigi dan mulut seseorang. Semakin baik tingkat pengetahuannya semakin baik pula perilaku atau tindakan seseorang dalam menjaga kesehatan gigi dan mulutnya.

Berdasarkan hasil penelitian ini, perlu diadakan promosi kesehatan gigi terhadap responden mengenai kebersihan gigi dan mulut pada masyarakat. Hal ini dimaksudkan agar masyarakat dapat mengerti dan memahami tentang kebersihan gigi dan mulut.

\section{KESIMPULAN}

Berdasarkan penelitian yang dilakukan pada bulan Mei 2019 pada pengunjung Poli Gigi Puskesmas Poigar, dapat disimpulkan :

1. Berdasarkan responden menurut indeks PHP menunjukkan bahwa responden dengan kategori sendang sebanyak 15 responden $(48,4 \%)$.

2. Berdasarkan jenis kelamin responden dengan indeks PHP tertinggi kriteria sedang pada responden jenis kelamin perempuan sebanyak 9 responden $(29,2 \%)$.

3. Berdasarkan kelompok umur responden dengan indeks PHP kategori sedang tertinggi pada umur 26 - 50 tahun sebanyak 10 responden $(32,3$

\section{SARAN}

Berdasarkan hasil dan pembahasan, maka disarankan kepada pasien pengunjung poli gigi puskesmas Poigar :

1. Diharapkan masyarakat Kecamatan Poigar Kabupaten Bolaang Mongondow agar lebih memperhatikan dan menjaga kebersihan gigi dan mulutnya dengan menyikat gigi secara teratur dan benar yaitu menyikat gigi 3 $\mathrm{x}$ sehari yaitu pagi sesudah sarapan pagi, siang sesudah makan dan malam sebelum tidur.

2. Pada masyarakat terlebih khusus bagi yang berjenis kelamin perempuan yang rentan akan terkena karies agar dapat memperhatikan kebersihan gigi dan mulutnya agar tidak menjadi risiko karies nantinya.

3. Bagi masyarakat Poigar berumur $26-50$ tahun yang merupakan usia produktif agar mendapat pengetahuan dari kader kesehatan atau tenaga medis di puskemas untuk menjaga kesehatan gigi dan mulutnya.

4. Mengkonsumsi buah - buahan yang berserat dan berair yang dapat membantu membersihkan gigi. 
5. Untuk peneliti selanjutnya agar meneliti variable lain yang berkaitan dengan Indeks PHP.

\section{DAFTAR PUSTAKA}

1. Putri, M. H., Herijulianti, E., \&Nurjana, N. (2010).Ilmu Pencegahan Penyakit-Penyakit Jaringan Keras dan Jaringan Pendukung Gigi. Buku Kedokteran EGC. Jakarta.

2. Kemenkes, RI. (2018). Riset Kesehatan Dasar. Badan Penelitian dan Pengembangan Tenaga Kesehatan Kemenkes. Jakarta

3. Pintauli S, Hamda T. (2010). Мепијu Gigi dan Mulut Sehat. Usu Press. Medan.

4. Mantiri, C.S. Wowor, S. N. V. Anindita, S. P (2013) Gambaran Status Kebersihan Gigi dan Mulut. Jurnal e-Gigi(eG), Volume 1 . Manado, diakses 14 Mei 2019.

5. Notoatmodjo, S (2018). Metodologi Peneliitian Kesehatan. Rineka Cipta. Jakarta.

6. Sudijono, (2015). Pengantar Statistik Pendidikan. Rajawali Pers, Jakarta

7. Hidayat, R. dan Tandiari, A. (2016).Kesehatan Gigi dan Mulut.CV Andi Offset.Yogyakarta.

8. Notoatmodjo, S. (2003). Ilmu Kesehatan Masyarakat. PT Rineka Cipta,Jakarta. 